\title{
Prescribed but not approved: biologic agents used without approval in juvenile idiopathic arthritis in Switzerland, France and Belgium
}

\author{
Andreas Woerner ${ }^{1,2^{*}}$, Alexandre Belot ${ }^{3}$, Etienne Merlin ${ }^{4}$, Carine Wouters ${ }^{5}$, Gerald Berthet ${ }^{6}$, Anuela Kondi $^{7}$, \\ Daniela Kaiser ${ }^{8}$, Laetitia Higel ${ }^{9}$, Anne Maes ${ }^{5}$, Elvira Cannizzaro ${ }^{10}$, Natalia Cabrera ${ }^{3}$, Silke Schroeder ${ }^{10}$, \\ Florence Aeschlimann ${ }^{10}$, Annette von Scheven ${ }^{2}$, Agnès Duquesne ${ }^{3}$, Samuel Roethlisberger ${ }^{2}$, Isabelle Kone-Paut ${ }^{11}$, \\ Michael Hofer ${ }^{2}$
}

From 21st European Pediatric Rheumatology (PReS) Congress

Belgrade, Serbia. 17-21 September 2014

\section{Introduction}

Biologic agents (BA) have profoundly changed the outcome of juvenile idiopathic arthritis (JIA), making inactive disease and clinical remission an achievable goal for treatment. An increasing number of BA has become available in the last 15 years. However, some BA that have been associated to efficacy in some clinical conditions are not approved by legal authority for the use in pediatric population.

\section{Objectives}

To evaluate the frequency of pediatric patients with JIA treated with BA not approved by medical supervisory authorities in Switzerland, France and Belgium at initiation of therapy.

\section{Methods}

Multicenter, retrospective study using the juvenile inflammatory rheumatism (JIR) cohort, including ten Swiss, French and Belgian centers for pediatric rheumatology.

\section{Results}

A total of 796 BA treatments in 531 patients were collected. Mean age at start of first biologic therapy was 10.9 (SD \pm 4.61 ) years. Etanercept, the first approved BA for pediatric use, was initiated in 378 patients (47.5\%), of whom 377 (99.7\%) after the approval date of the European medical agency (EMA) or Swissmedic (SM).

'Pediatric Rheumatology, University Children`s Hospital, Basel, Switzerland Full list of author information is available at the end of the article
Adalimumab, infliximab and golimumab were used in $147(18.5 \%), 106(13.3 \%)$ and $14(1.8 \%)$ patients, respectively; $75(51.0 \%)$ patients were started on adalimumab before EMA/SM approval, whereas all patients on infliximab and golimumab were treated without EMA/SM approval. Abatacept was given in 26 patients (3.3\%), of whom in 10 patients (38.5\%) before EMA/SM approval. Tocilizumab was used in a total of 48 patients (6.0\%); for systemic-onset JIA and non-systemic JIA, it was prescribed in 5 of 28 patients (17.9\%) and 16 of $20(80 \%)$ before EMA/SM approval, respectively. Canakinumab used for the treatment of systemic-onset JIA was given in 14 patients $(77.8 \%)$ without approval for this indication. Anakinra was identified in 49 patients (6.3\%) for the treatment of systemic-onset JIA, although EMA/SM approval is pending for this disease. When more than one BA was used in a patient, 167 out of 265 treatments (63\%) were given without approval. In total, 300 treatments $(37.7 \%)$ were started without authorization by EMA/SM.

\section{Conclusion}

In pediatric rheumatology clinical practice, a significant number of BA lacks authority approval for the treatment of JIA. Pediatric clinical trials and registers are crucial to assess effectiveness and safety of BA in this rare disease, substantiating an unequivocal decision making of both doctors and their patients.

\section{Disclosure of interest}

None declared. 


\section{Authors' details}

${ }^{1}$ Pediatric Rheumatology, University Children's Hospital, Basel, Switzerland. ${ }^{2}$ Rhumatologie pédiatrique Romande, Centre Hospitalier Universitaire Vaudois, Lausanne, Switzerland. ${ }^{3}$ Pediatric Rheumatology, Hôpital Femme Mère Enfant, Lyon, France. ${ }^{4}$ Pediatrics, Centre Hospitalier Universitaire, Clermont-Ferrand, France. ${ }^{5}$ Pediatric Rheumatology, University Hospital, Leuven, Belgium. ${ }^{6}$ Pediatrics, Children's Hospital, Aarau, Switzerland.

${ }^{7}$ Pediatrics, Kremlin-Bicêtre Hospital, Paris, France. ${ }^{8}$ Pediatrics, Children`s Hospital, Lucerne, Switzerland. ${ }^{9}$ Pediatrics, Hôpital Hautepierre, Strasbourg, France. ${ }^{10}$ Pediatric Rheumatology, University Children's Hospital, Zuerich, Switzerland. ${ }^{11}$ Pediatric Rheumatology, Kremlin-Bicêtre Hospital, Paris, France.

Published: 17 September 2014

doi:10.1186/1546-0096-12-S1-P338

Cite this article as: Woerner et al:: Prescribed but not approved: biologic agents used without approval in juvenile idiopathic arthritis in Switzerland, France and Belgium. Pediatric Rheumatology 2014 12(Suppl 1):P338.

\section{Submit your next manuscript to BioMed Central} and take full advantage of:

- Convenient online submission

- Thorough peer review

- No space constraints or color figure charges

- Immediate publication on acceptance

- Inclusion in PubMed, CAS, Scopus and Google Scholar

- Research which is freely available for redistribution

Submit your manuscript at www.biomedcentral.com/submit
Ciomed Central 